\title{
Report of the incidence of a new rare strain of Cladosporium species and incidence of three other Cladosporium species in the intramural environment of Bengaluru, India
}

\author{
Jyoti Bharamgoud Marigoudar ${ }^{1 *}$, Narendra Kuppan ${ }^{2}$ \\ ${ }^{1}$ Department of Botany, Post Graduate Research Centre, St. Joseph's college (Autonomous). Langford road, Bengaluru, Karnataka, \\ India. \\ ${ }^{2}$ Department of Botany, Annamalai University, Chidambaram, India.
}

\begin{tabular}{l}
\hline ARTICLE INFO \\
\hline Article history: \\
Received on: May 05, 2021 \\
Accepted on: September 04, 2021 \\
Available online: February 15, 2022 \\
\hline
\end{tabular}

Key words:

Cladosporium, aeromycoflora,

CFUs, GenBank accession number

\begin{abstract}
The prevalence of airborne Cladosporium was investigated for seasonal occurrence in the internal environment (bedroom) in two adjacent localities of Bengaluru. The foremost objective was to study the fungal diversity in air by culturing it on nutrient media from April 2018 to March 2019. The incidence of airborne Cladosporium species exhibited significant deviation in the localities. The sampling exhibited the highest number of Cladosporium species in the winter. Cladosporium oxysporum showed the highest prevalence, followed by Cladosporium bruhnei, Cladosporium cladosporioides, and Cladosporium herbarum. The period with a highest value of CFUs (Colony Forming Units) concentration interrelated with seasonal distribution indoor aerofungi. The current study also involved the first time molecular characterization of a new rare strain of $C$. bruhnei obtained from the bedroom. Using $18 \mathrm{~S}$ rDNA sequencing, the new strain (LP3CO) was identified. The sequence was submitted to the GenBank and an accession number was established. The major fungal species identified from the bedrooms were associated with the results obtained from fungal allergen detection tests carried out on respiratory allergy patients in a major hospital in Bengaluru.
\end{abstract}

\section{INTRODUCTION}

A major portion of the air-spora consists of airborne fungal spores. These airborne fungal spores have an important role in the cause of respiratory allergy. The 19th century witnessed breakthrough discoveries pertaining to aero-biology by Blackley [1], Nilsby [2], Kramer and Pady [3], Sandhu et al. [4], and Hasnain et al. [5], who also proved the trivial role of fungal spores in the cause of respiratory allergy. Among the airborne fungal spores, various species of Cladosporium are prevailing and prominently present in the air. The report from all over the world now clearly showed that fungal spores engage in the recreation of an important part in the etiology of respiratory allergic disorders. When a sensitive individual inhales the aerial fungal spores, allergic symptoms are noticed. Fungal spores

\footnotetext{
*Corresponding Author

Jyoti Bharamgoud Marigoudar, Department of Botany, Post Graduate and Research Centre, St. Joseph's College (Autonomous), Bengaluru, India. E-mail: jyotimarigoudar@gmail.com
}

lack "chlorophyll," therefore they live as a saprophyte or parasite in nature. The present study reports the prevalence of various species of airborne Cladosporium from the bedrooms in Bengaluru. The prologues intend that the hospital survey was to know the prevalence of respiratory allergy caused by airborne fungi.

\section{MATERIALS AND METHODS}

\subsection{Study Sites}

\subsubsection{Site 1}

Malleshwaram is located in the northwestern part of Bengaluru. It is one of the oldest, antique, residential areas. It has several educational institutions, commercial buildings, and government offices. As a residential area, it has many avenue trees and spacious gardens. It hosts several avenue trees like Mangifera, Tamarindus, Bauhinia, Spathodea, Tabebuia, Millingtonia hortensis, Samanea saman, Delonix regia, etc. The experimental site for the study was the ground floor of a house in the northwestern part of 
Malleshwaram. The house measured 850 sq. $\mathrm{ft}$. and the bedroom measured 100 sq. ft. Small buildings (with three to four floors) were generally present in the area. All of them had natural light and ventilation. Plants in the immediate vicinity of the site were Artocarpus heterophyllus, Nyctanthes sp., Cocos nucifera, Eucalyptus globulus, Polyalthia longifolia, and Carica papaya. The educational institutions nearby had copious vegetation. Next to the site was an old, empty bungalow with a small garbage dumping yard.

\subsubsection{Site 2}

Subramanya Nagar is a residential locality and a business hub in the northwestern part of Bengaluru. This study site was on the eighth floor of the apartment building. The apartment measured 1,000 sq. $\mathrm{ft}$. and the bedroom measured $120 \mathrm{sq}$. ft. The area was clean with good ventilation. The apartment was surrounded by Eucalyptus globulus, Tamarindus indica, Saraca indica, Cassia siamea, Michelia champaca, Delonix regia, Casuarina equisetifolia, and Cocos nucifera. It was $100 \mathrm{~m}$ away from a train track.

\subsection{Intramural Samplings}

Air samplings were taken for a period of 1 year from April 2018 to March 2019 at weekly intervals (every Monday), between $6 \mathrm{pm}$ and $8 \mathrm{pm}$. Five replicated media plates $(9 \mathrm{~cm}$ in diameter) containing Martin's Rose Bengal Streptomycin Agar with streptomycin (50 $\mathrm{mg}^{-1}$ ) were carried to the study sites in sterilized containers and the media plates were exposed 2 feet from the floor in the bedrooms to avoid dust. The exposure time was standardized at 10 minutes to the bedroom air to receive the sedimentation of the airborne indoor fungal spores on the media plates. After exposure, each set of plates was brought separately to the Mycology Laboratory, Department of Botany, St. Joseph's College (Autonomous), Bengaluru, with utmost care and incubated at room temperature upside down for a total of 14 days (Figs. 1 and 2) with steady, consistent observation. After 3-4 days of incubation, fungal CFUs developed in the plates and they were counted for individual species to get the total number of Cladosporium CFUs. The fifth petri plate was kept unopened but incubated as a control plate to check any contamination during the preparation of the medium.

\subsection{Identification of Selected Fungi}

\subsubsection{Morphological identification}

The identification of different airborne fungi was carried out with the help of slides prepared by direct mounting from the CFUs. Laboratory experience, expertise by using fungal spore reference slides (prepared from disease infected plants), and taxonomic literature by Barnett [6], Domsch et al. [7], Sutton et al. [8], Kirk et al. [9], and Dube [10] were employed to categorize the fungi to their respective taxa. Annual, monthly, and seasonal percentage occurrences of individual species were determined.

\subsubsection{Molecular identification}

Identification of fungi was authenticated by $18 \mathrm{~S}$ rDNA technology. GenBank accession numbers were obtained from the National Center for Biotechnology Information (NCBI) for the selected
Cladosporium fungi. This technique was adopted when doubts about their species level persisted even after pure culture. As the name of this species was necessary with regard to the allergen testing at the hospital, it was crucial that their exact identities (species level) were obtained. The identity of the species was confirmed as Cladosporium bruhnei, with accession number MH879819.

\subsection{Data Analysis}

The incidence of Cladosporium CFUs of two sites was calculated by standard deviation using the following formula:

$$
\sigma=\sqrt{\frac{\sum X^{2}}{n}-\frac{\sum X^{2}}{n}}
$$

where:

$\sigma=$ Standard deviation

$\Sigma X=$ Addition of all the CFUs;

$n=$ Quantum of the population

\section{RESULTS AND DISCUSSION}

The results of the 1 year aeromycological survey revealed that the bedrooms were never free from fungal spores. The fungal diversity varied with season and weather. A total of 4 Cladosporium species and 463 Cladosporium CFUs were recorded from the two sites.

\subsection{Seasonal Variations of Aeromycoflora}

In site-1 Malleshwaram, November and January were high CFU months, whereas the number of CFUs recorded in May and March

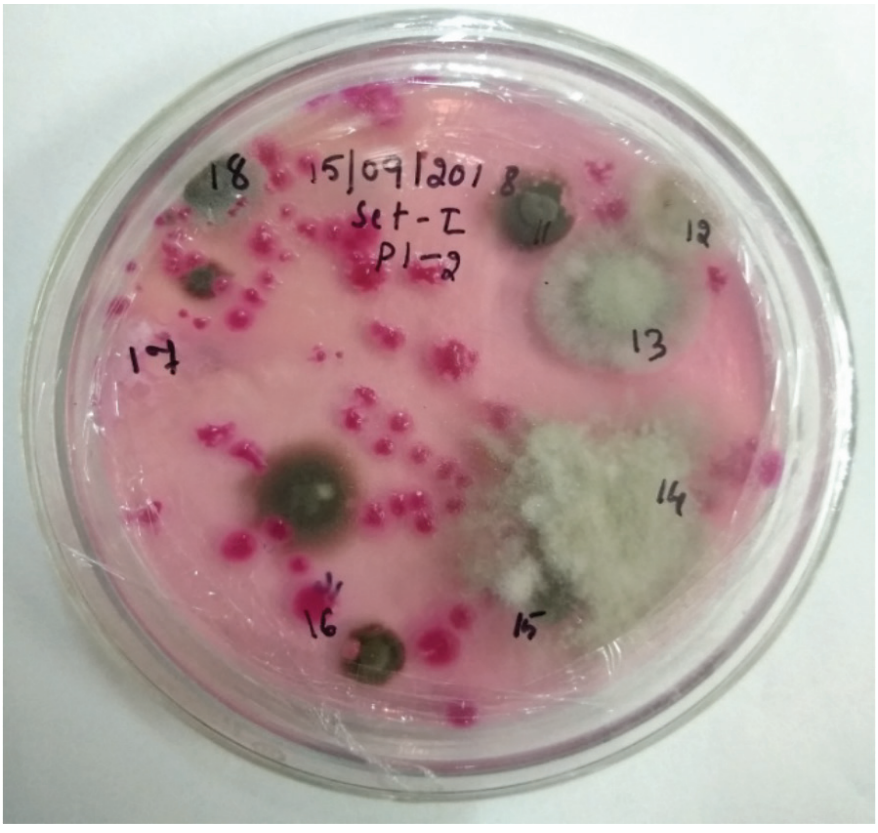

Figure 1: Exposed petri plates showing fungal colonies in sampling year 2018 from site- 1 . 
was low (Fig. 3). In site-2 Subramanya Nagar, February and August showed a high incidence of CFUs. As for the abovementioned domino effect, it is manifested that the CFU concentrations were not consistent throughout the year (Tables 1 and 2). RodríGuezRajo [11], Ponce-Cabellero et al. [12], Mohture and Kalkar [13], and Priyamvada et al. [14] reported on the seasonal variations of arboreal mycoflora.

The winter season indicated the highest number of Cladosporium CFUs (48.95\%, Fig. 4 and 35.59\%, Fig. 5) in the intramural environment. This may be associated to the stumpy minimum temperature which is appropriate for fungal augmentation and increase in CFUs. Winter which begins at the end of northeast monsoon favors the prompt growth of fungi. The moisture provided by the tail end of the monsoon and cooler months of the winter help in the proliferation of fungi and their dispersal. The fungal spores are usually dissipated from the conidiophores by hydrostatic pressure and airstream. The dry months of summer

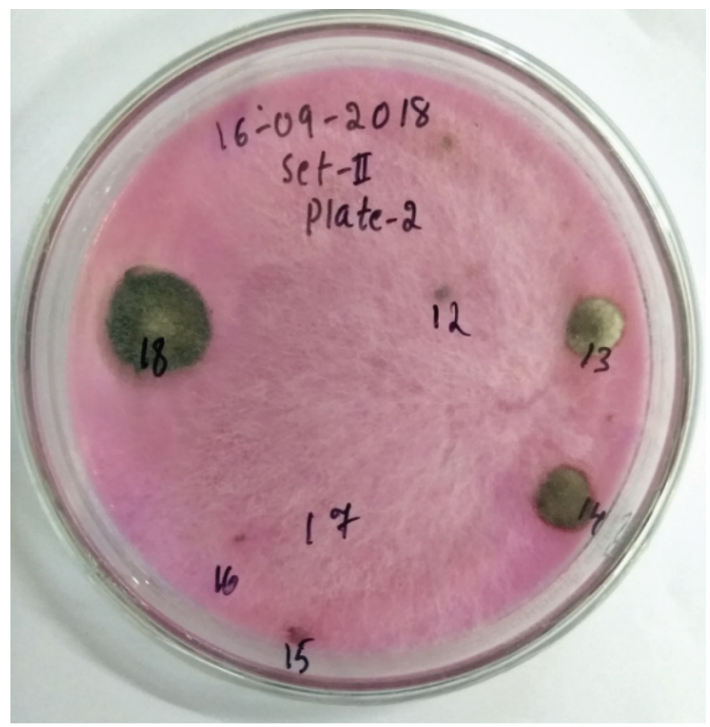

Figure 2: Exposed petri plates showing fungal colonies in sampling year 2018 from site- 2 . with the paucity of moisture inhibits fungal growth. Trujillo Jurado et al. [15], Kuo and Li [16], Ren et al. [17], Medrela-Kuder [18] and RodríGuez-Rajo et al. [11] reported the dominance of airborne fungi in winter.

The rainy season contributed to moderate spores (in site-1: $26.57 \%$ CFUs and in site-2: $33.33 \%$ CFUs). The rainy season showed the second highest dominance of CFUs. Rains scrub out fungal spores from the atmosphere and rain drops also would have served to form conditions which are favorable for fungal growth. The settling and draining of the fungal spores in rain water would have caused restricted entry of spores indoors. Agarwal and Shivpuri's [19] survey supports this result. Extreme heat and cold cause adverse effects for the formation of fungal spores. The summer season showed a much lesser number of Cladosporium CFUs.

\subsection{Qualitative and Quantitative Variations of the Aeromycoflora}

A perusal of Table 3 and Figures 6 and 7 indicates that Cladosporium oxysporium is the leading arboreal mycoflora species (212 CFUs). November and January showed the highest densities of CFUs. March and July were least concentration months in sites 1 and 2.

Quantitative analysis revealed that C. bruhnei (Figs. 8 and 9) was the second in concentrations. It was predominantly second (site-1) and first (site-2) in both sites. Tables 1 and 2 show the relative occurrence of $C$. bruhnei was more in October at site-1 and in September and January at site-2. Relative incidence of $C$. cladosporoides (Fig. 10) was high in July and September in site-1 and February at site-2.

\subsection{Confirmation of Airborne Cladosporium sp. by Molecular Identification}

Cladosporium bruhnei is one of the prevailing common arboreal mycoflora Cladosporium species in the study. It is a lesser familiar airborne fungi and reports pertaining to the fungi are inadequate. So it was determined to conduct a molecular level study. Gene sequencing of $18 \mathrm{~S}$ rDNA of C. bruhnei (Fig. 11) was carried out, and it showed that $C$. bruhnei was a new rare strain. The $18 \mathrm{~S}$ rDNA

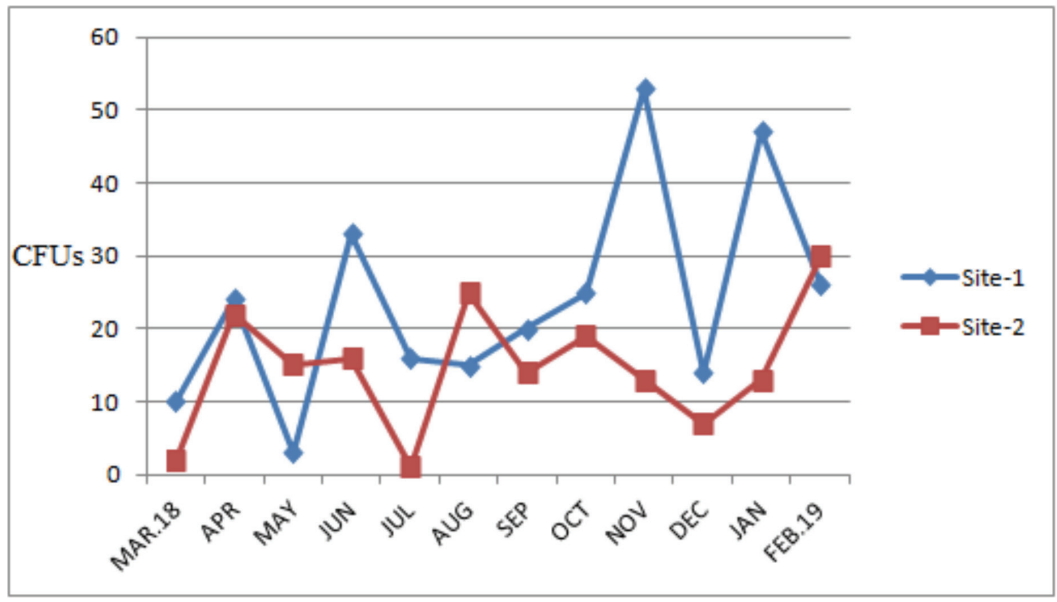

Figure 3: Monthly incidence of Cladosporium CFUs in site-1 and site-2. 
Table 1: Colonies of Cladosporium isolated (March 2018 to February 2019) in site-1.

\begin{tabular}{|c|c|c|c|c|c|c|c|c|c|c|c|c|c|}
\hline Fungi & Mar. 18 & Apr & May & Jun & July & Aug & Sep & Oct & Nov & Dec & Jan & Feb.19 & $\begin{array}{l}\text { Total no. } \\
\text { of CFUs }\end{array}$ \\
\hline C. oxysporium & 7 & 18 & 2 & 23 & 2 & 1 & 1 & 3 & 43 & 13 & 41 & 25 & 179 \\
\hline C. bruhnei & 3 & 6 & 1 & 8 & 4 & 6 & 10 & 19 & 6 & - & 5 & - & 68 \\
\hline C. cladosporioides & - & - & - & 2 & 9 & 8 & 9 & 3 & 4 & 1 & 1 & - & 37 \\
\hline Cladosporium herbarum & - & - & - & - & 1 & - & - & - & - & - & - & 1 & 2 \\
\hline Total & 10 & 24 & 3 & 33 & 16 & 15 & 20 & 25 & 53 & 14 & 47 & 26 & 286 \\
\hline
\end{tabular}

Table 2: Colonies of Cladosporium isolated (April 2018-March 2019) in site-2.

\begin{tabular}{|c|c|c|c|c|c|c|c|c|c|c|c|c|c|}
\hline Fungi & Apr. 18 & May & Jun & Jul & Aug & Sep & Oct & Nov & Dec & Jan & Feb & Mar.19 & $\begin{array}{l}\text { Total no. } \\
\text { of CFUs }\end{array}$ \\
\hline C. cladosporioides & 7 & - & 2 & - & 10 & 4 & 13 & 7 & 3 & - & 14 & - & 60 \\
\hline C. oxysporum & 8 & 5 & 5 & - & 7 & - & - & - & - & 2 & 6 & - & 33 \\
\hline C. herbarum & 6 & 2 & - & - & 1 & - & 3 & - & 4 & 1 & 5 & - & 22 \\
\hline Total & 22 & 15 & 16 & 1 & 25 & 14 & 19 & 13 & 7 & 13 & 30 & 2 & 177 \\
\hline
\end{tabular}

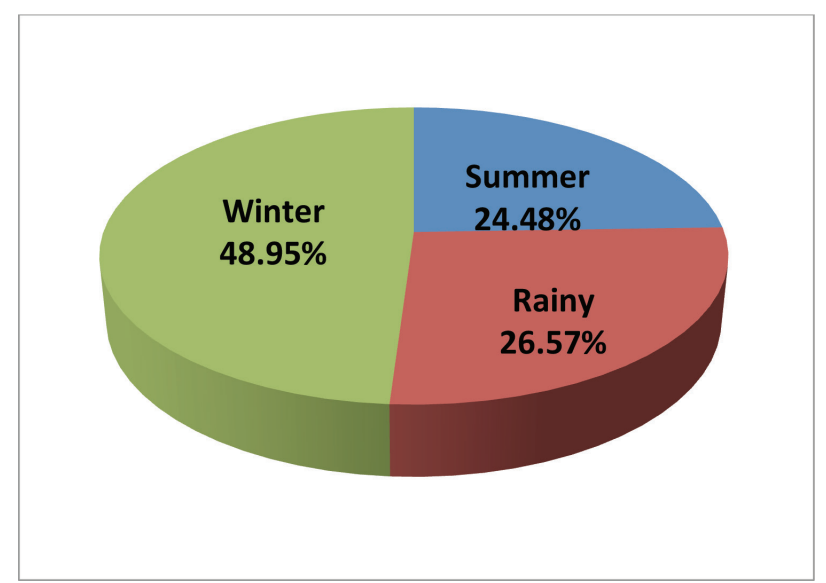

Figure 4: Percentage incidence of arboreal fungal spores based on the season (March 2018-February 2019), site-1.

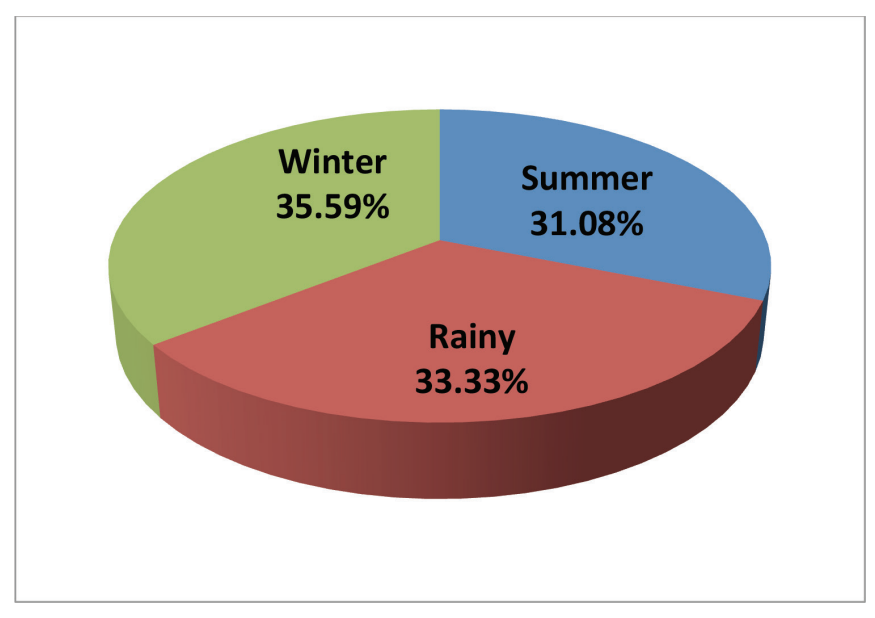

Figure 5: Percentage incidence of arboreal fungal spores based on the season (April 2018-March 2019), site-2.

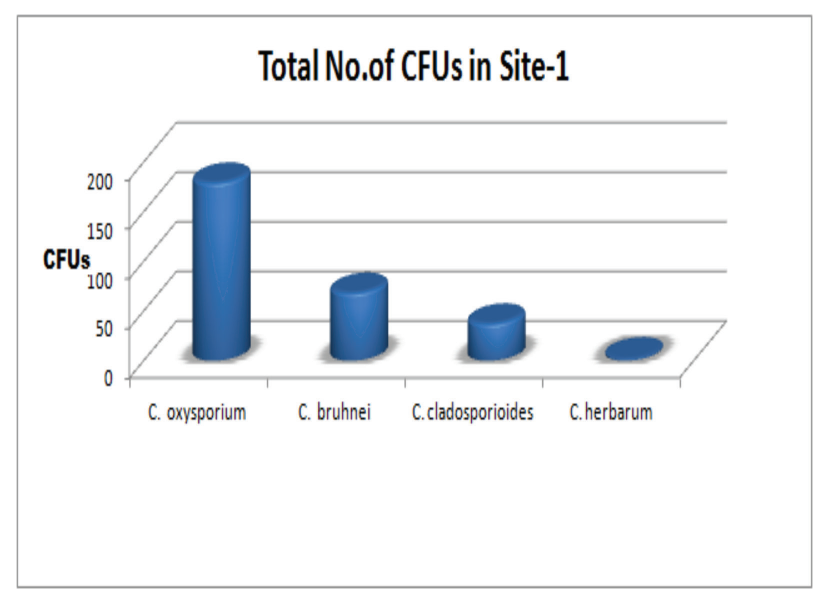

Figure 6: Cladosporium species prevalence in site-1.

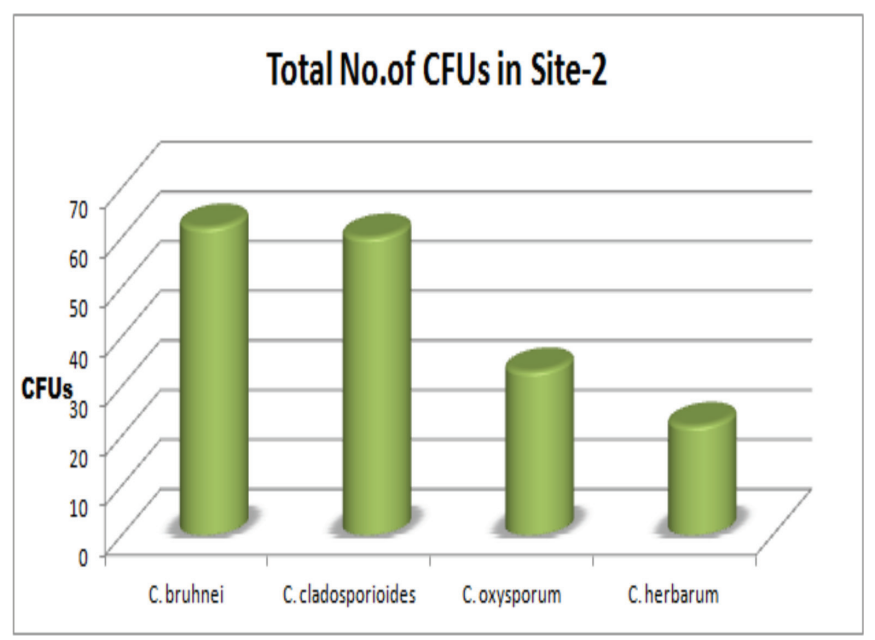

Figure 7: Cladosporium species prevalence in site-2. 


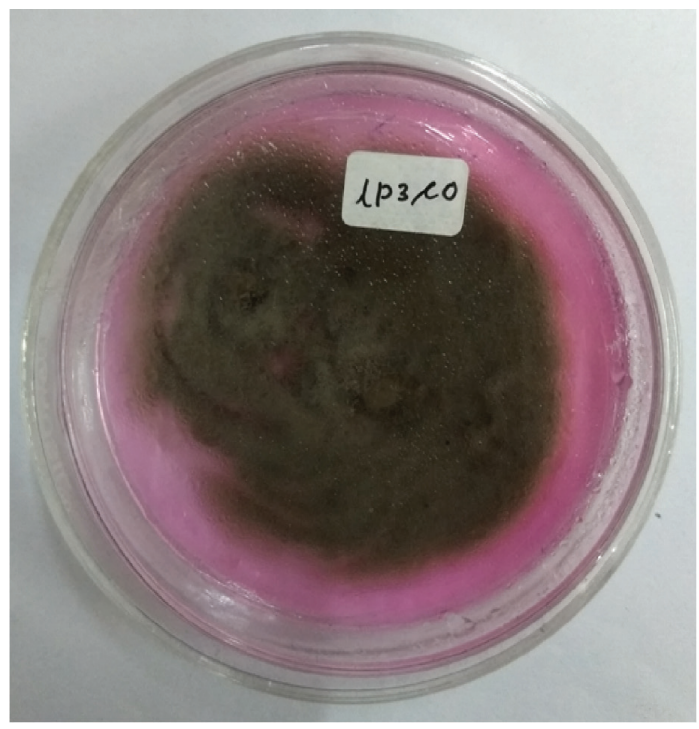

Figure 8: Pure culture of C. bruhnei.

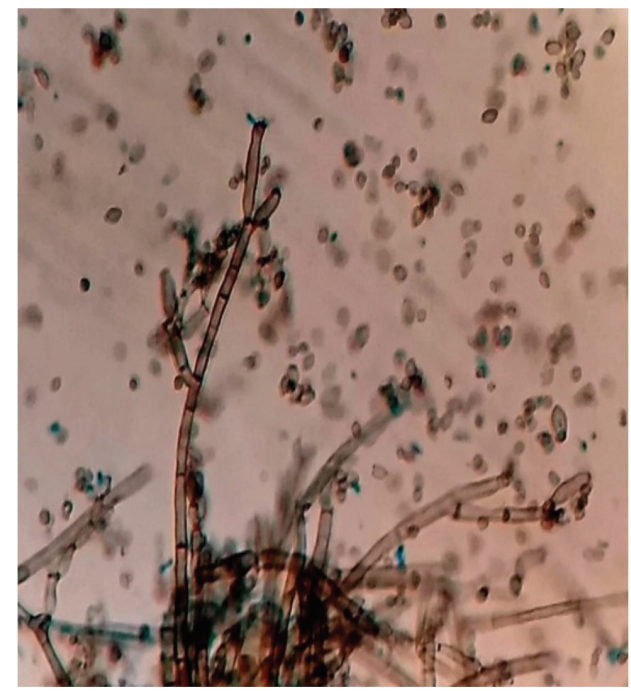

Figure 9: Colony morphology and microphotographs of endophytic fungi $C$. bruhnei.

sequence data of the airborne fungal isolate from bedroom LP3CO was closely related to $C$. bruhnei. Gene sequence of $C$. bruhnei was deposited at the NCBI with the GenBank accession number MH879819. A phylogenetic tree of intramural airborne fungal isolate is shown in Figure 12. Cladosporium bruhnei showed 99\% the homology along with its isolates.

\subsection{Vertical Distribution of Cladosporium Spores}

It was observed that the standard deviation of spores in site- 1 was 14.04 and in site-2 10.63. The higher fungal concentration at ground level may be owing to the variations of microclimate inside the bedrooms (Table 3). One of the reasons for variations in the bedroom microclimate could be the change in the weather outside. In addition, the ground floor of the house is very near

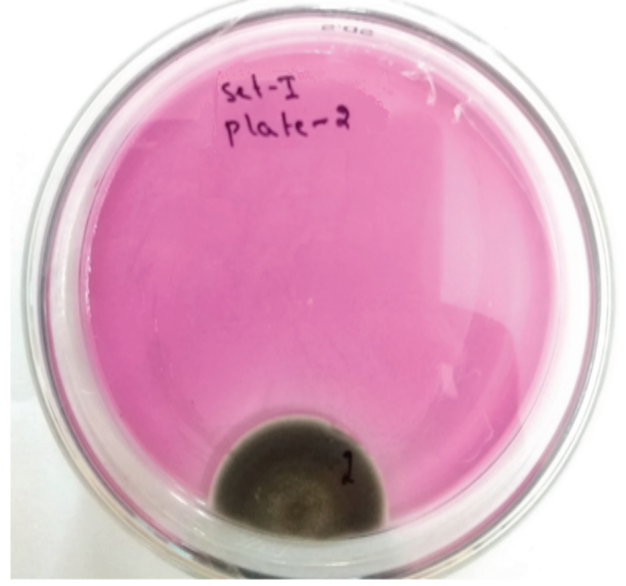

Figure 10: An exposed plate of C. cladosporioides obtained as a pure colony from site-1.

$\begin{array}{llllll}1 & 2 & 3 & 4 & \text { L }\end{array}$

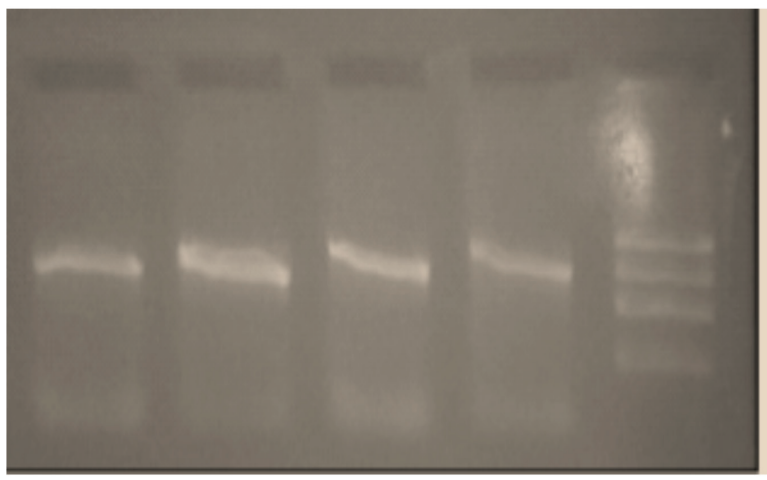

Lane description: 3. Sample LP3CO 5. L-DNA Marker

Figure 11: PCR amplification of 18S rDNA fragment from samples.

to the surrounding vegetation, decomposing litter, plant debris, and garbage dumping yard. Lacey [20] reported the difference in aeromycoflora of two sites influenced by microclimate of the bedroom and also local flora.

\subsection{Analysis of the Survey Conducted on Respiratory Allergy Patients}

A survey on respiratory allergy patients was carried out at St. John's Medical College Hospital, a major hospital in Bengaluru. Data were collected from January 2014 to June 2019. The preliminary aim of this investigation was to know the prevalence of respiratory allergy caused by airborne fungi. Doctors of the ENT out-patient department of the hospital carried out allergen detection test (Skin Prick test). It is an intradermal test used to detect offending fungal allergens of respiratory allergy patients.

A total of 437 respiratory allergy patients were tested with pollen, dust mite, food, dander, and fungal antigens. Out of the 437 


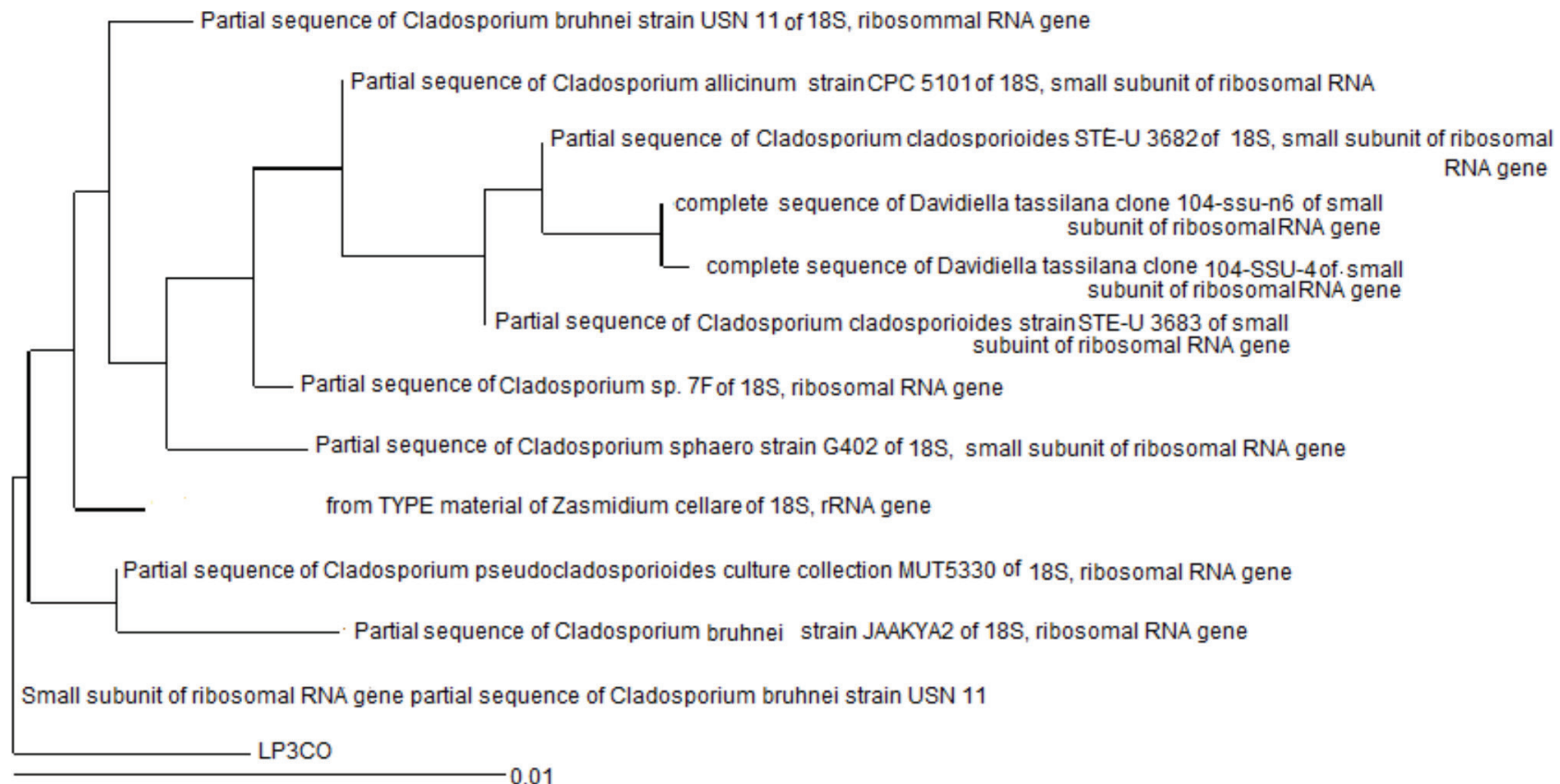

Figure 12: Phylogenetic tree of C. bruhnei with Genbank accession number MH879819.

Table 3: Monthly occurrence of Cladosporium (April 2018-March 2019) from site-1 and site-2.

\begin{tabular}{lcccccccccccccc} 
Site & Mar. 18 & Apr & May & Jun & Jul & Aug & Sep & Oct & Nov & Dec & Jan & Feb. 19 & Total \\
Site-1 & 10 & 24 & 3 & 33 & 16 & 15 & 20 & 25 & 53 & 14 & 47 & 26 & 286 \\
Site-2 & 2 & 22 & 15 & 16 & 1 & 25 & 14 & 19 & 13 & 7 & 13 & 30 & 177 & 50 \\
Total & 12 & 46 & 18 & 49 & 17 & 40 & 34 & 44 & 66 & 21 & 60 & 56 & 463 \\
\hline
\end{tabular}

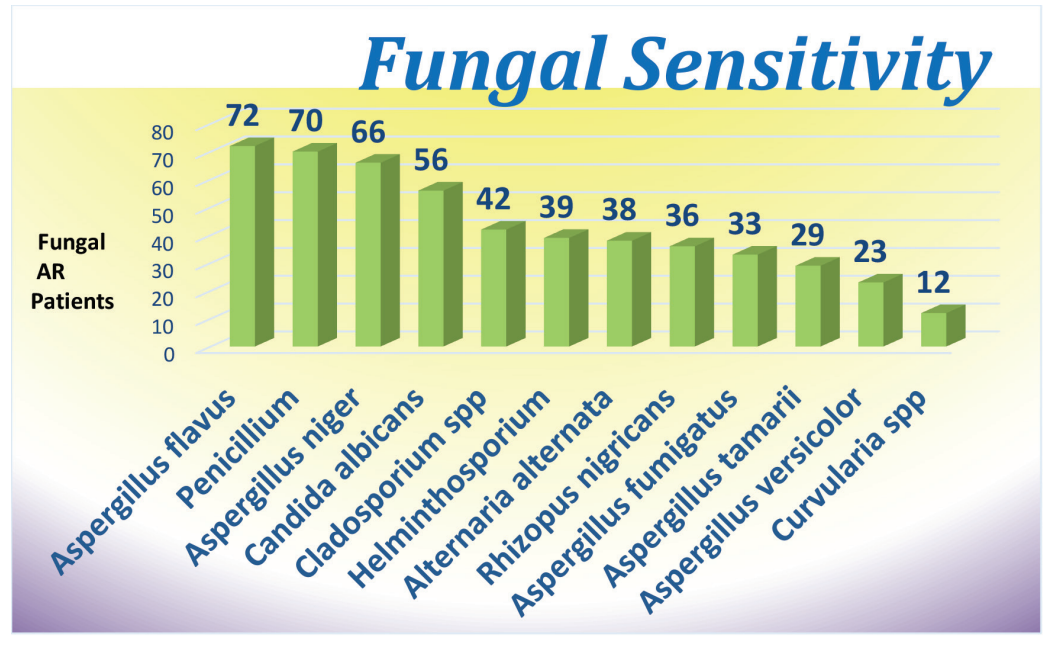

Figure 13: Number of positive reactions seen in 184 patients' demography.

respiratory allergy patients tested, 184 patients $(42.10 \%)$ showed positive reactions to diverse fungal allergens. The actuality that $22.83 \%$ of the respiratory allergy patients showed fungal allergy to Cladosporium was quite significant (Fig. 13).

\section{CONCLUSION}

Cladosporium is the most familiar indoor fungi recorded in our investigation. In non-temperate environment conditions, these fungi are the most prevalent and are known for their respiratory allergy. 
The survey shows Cladosporium to be one of the leading aerofungi. This might possibly be an air allergen. The ground floor house showed more density of aerofungi compared to the eighth floor house. The results showed that small houses with bigger number of possession and lack of sanitation designate soaring incidence of aerofungi. The conspicuous difference in the concentration of Cladosporium species in the two study sites can also be endorsed to the height of the residence from ground level and the ground floor site which is in close proximity to the nearby vegetation, dead, decaying litter, and garbage dumping yard.

The present study underlines the need for more Cladosporium species to be tested on respiratory allergy patients. Three fungal species, namely $C$. oxysporium, C. bruhnei, and Cladosporium cladosporioides, which were found in significant numbers in this study, are presently not being tested on patients separately.

This study finally emphasizes the need and recommends collaboration between doctors and mycologists to select the right fungal antigens for testing on patients with respiratory allergy. The use of appropriate antigens can lead to better detection of allergens and subsequent effective treatment and management of respiratory allergies.

\section{ACKNOWLEDGMENTS}

The authors are thankful to the Research Guide Dr. Jacob N. Abraham [Associate Professor, Post-Graduate Department of Botany and Research Center, St. Joseph's College (Autonomous)], Bengaluru, for his valuable guidance, keen interest, and constant encouragement. The authors are also thankful to Department of Botany and Research Center, St. Joseph's College (Autonomous), Bengaluru.

\section{AUTHOR CONTRIBUTIONS}

All authors made substantial contributions to conception and design, acquisition of data, or analysis and interpretation of data; took part in drafting the article or revising it critically for important intellectual content; agreed to submit to the current journal; gave final approval of the version to be published; and agree to be accountable for all aspects of the work. All the authors are eligible to be an author as per the international committee of medical journal editors (ICMJE) requirements/guidelines.

\section{FUNDING}

There is no funding to report.

\section{CONFLICTS OF INTEREST}

The authors report no financial or any other conflicts of interest in this work.

\section{ETHICAL APPROVALS}

This study does not involve experiments on animals or human subjects.

\section{REFERENCES}

1. Blackley $\mathrm{CH}$. Experimental researches on the causes and nature of Catarrhus aestivus (hay-fever or hay-asthma). Bailliere, London, UK, 1873.
2. Nilsby L. Allergy to moulds in Sweden. Acta allergol 1949;II:57-90.

3. Kramer CL, Pady SM. Kansas aeromycology XI: fungi imperfecti Trans Kans Acad Sci 1960;63:228-37.

4. Sandhu DK, Shivpuri DN, Sandhu RS. Studies in the air-borne fungal spores in Delhi. Their role in respiratory allergy. Ann Allergy 1964;22:374-84.

5. Hasnain SM, Al-Frayh A, Gad-el-rab MO, Al-Sedairy S. Airborne Alternaria spores: potential allergic sensitizers in Saudi Arabia. Ann Saudi Med 1998;18:497-501.

6. Barnett HL. Illustrated genera of imperfect fungi. 2nd edition, Burgess Publishing Company, Minneapolis, MN, pp 1-221, 1960.

7. Domsch KH, Andeson TH, Gams W. Compodium of soil fungi. Academic press, London, UK, vol. 2, pp 1-18, 1980.

8. Sutton DA, Fothergill A, Rinaldi MG. Guide to clinically significant fungi. Williams and Wilkins press, Baltimore, MD, 1998.

9. Kirk PM, Cannon PF, Minter DW, Stalpers JA. Dictionary of the fungi, CABI, Wallingford, UK, 2008.

10. Dube HC. Fungi, Bacteria and Viruses. Agrobios, Jodhpur, India, 2010.

11. RodrÍGuez -Rajo RF, Iglesias I, Jato V. Variation assessment of airborne Alternaria and Cladosporium spores at different biological conditions. Mycol Res 2005;109:1-6.

12. Ponce-Cabellero C Gamboa-Marrufo M, López-Pacheco M, CerónPalma I, Quintal-Franco C, Giácoman-Vallejos G, et al. Seasonal variation of airborne fungal propagules indoor and outdoor of domestic environments in Merida, Mexico. Atmosfera 20013;26(3):369-77.

13. Mohture VM, Kalkar SA. Aeromycological investigation in the atmosphere of Nagpur, Maharashtra (India). Int J App Res 2017;3(3):166-9.

14. Priyamvada H, Singh, RK, Akila M, Ravikrishna R, Verma RS, Gunthe SS. Seasonal variation of the dominant allergenic fungal aerosols-one year study from southern Indian region. Sci Rep 2017;11:1-12.

15. Trujillo Jurado D, Infante García-Pantaleón F, Galán Soldevilla C, Domínguez Vilches E. Seasonal and daily variation of Aspergillus Mich. Ex Fr. Spores in the atmosphere of Cordoba (Spain). Allergol Immunopathol (Madr) 1990;18(3):167-73.

16. Kuo YM, Li CS. Seasonal fungus prevalence inside and outside of domestic environments in the subtropical climate. Atmos Environ 1994;28(19):3125-30.

17. Ren P, Jankun TM, Leaderer BP. Comparison of seasonal fungal prevalence in indoor and outdoor air and in house dusts of dwellings in one northeast America country. J Exposure Sci Environ Epidemiol 1999;(6):560-8.

18. Medrela-Kuder E. Seasonal variations in the occurrence of culturable airborne fungi in outdoor and indoor air in Cracow. Int Biodeterior Biodegrad 2003;52:203-5.

19. Agarwal MK, Shivpuri DN. Fungal spores, their role in respiratory allergy. Adv Pollen Spores Res 1974;1:78-128.

20. Lacey ME. The summer airspora of two contrasting adjacent rural sites. Microbiology 1962;29:485-501.
How to cite this article:

Marigoudar JB, Narendra K. Report of the incidence of a new rare strain of Cladosporium species and incidence of three other Cladosporium species in the intramural environment of Bengaluru, India. J Appl Biol Biotech 2022; 10(02):89-95. 